\section{Authors response. The chronic obstructive pulmonary disease (COPD) control panel: towards personalised medicine in COPD}

We thank Dr Vishnivetsky et $a l^{1}$ for their interest in our paper on the 'COPD control panel'. We are happy to see that our proposal has generated some debate. In their letter, Dr Vishnivetsky and colleagues raise several important issues: (1) Relevance of comorbidities. We fully agree with their comments. Whether or not they should be 'prioritised' in the control panel proposed is open for debate. First, we are not sure that we understand what they mean by 'prioritised'. Comorbidities are already part of the proposal. Perhaps they are suggesting that comorbidities deserve a specific module with individual comorbidities within it. We are not against this and, in fact, we never pretended that ours should be a 'final' proposal. On the contrary, our intention was to generate debate among the scientific community (such as this one) in order to advance and, eventually, agree (after appropriate scientific validation) on the modules and variables to include. Our key idea was that COPD is a complex disease, and that several domains of the disease (such as severity, activity, impact and eventually, 'omics') will need to be considered if we really want to advance towards a much more personalised approach to COPD assessment and management; (2) Implementation in clinical practice. The issue of implementation in practice is, of course, important. As we indicate in our proposal, currently available technology can help us simplifying its practical use (eg, an 'app'); (3) Severity and control panels. Today, we do believe that it is important to recognise the differences in the three aspects of COPD - severity, activity and impact of disease. However, it may be that future rigorous research concludes that two panels (severity and control) are enough to characterise and guide therapy in COPD. In any case, we will be very happy if the scientific community considers our proposal a useful first step.

\section{Alvar Agusti, ${ }^{1,2}$ William MacNee ${ }^{3}$}

${ }^{1}$ Thorax Institute, Hospital Clinic, IDIBAPS, University of Barcelona, Barcelona, Spain 
${ }^{2}$ FISIB, CIBER Enfermedades Respiratorias Mallorca, Spain

${ }^{3}$ ELEGI Colt Laboratories, MRC/UoE Centre for inflammation Research, Queen's Medical Research Institute, Edinburgh, UK

Correspondence to Professor Alvar Agusti, Thorax Institute, Hospital Clinic, University of Barcelona, IDIBAPS, Villarroel 170, Escala 3, Planta 5, Barcelona 08036, Spain and and FISIB, CIBER Enfermedades Respiratorias Mallorca, Spain;

alvar.agusti@clinic.ub.es
Contributors Both authors contributed equally to this paper and to the response to the Letter to the Editor.

Competing interests None.

Provenance and peer review Commissioned; internally peer reviewed.

To cite Agusti A, MacNee W. Thorax 2013;68:389-390.

Received 5 December 2012

Accepted 6 December 2012

Published Online First 8 January 2013

\section{Linked}

- http://dx.doi.org/10.1136/thoraxjnl-2012-203056

Thorax 2013:68:389-390.

doi:10.1136/thoraxjnl-2012-203090

REFERENCE

1 Vishnivetsky II, Dyadyk O, Mostovoy Y. The place of comorbidities in "COPD control panel" Thorax 2013;68:388-9. 